\title{
Microwave - Assisted Synthesis of Flavones and their Comparative Study with Conventational Method.
}

\author{
${ }^{1}$ Belsare D .P, ${ }^{2}$ Kazi Aasim* \\ ${ }^{1}$ Department of Pharmaceutical Chemistry, \\ NDMVP'S College of pharmacy, Gangapur road,Nashik-422002, \\ Maharashtra,India \\ ${ }^{2}$ Department of Pharmaceutical Chemistry, \\ Sandip Foundation's SIPS, Mahirawani,Trimbak road, Nashik-422 213.
}

\begin{abstract}
A Series Of 3-Hydroxyflavones Were Synthesized In Microwave Oven And By Conventional Method. Derivatives Of 3-Hydroxyflavones Were Synthesized From 2'-Hydroxychalcones Using Hydrogen Peroxide And Sodium Hydroxide In Microwave. In This Investigation 2'-Hydroxychalcones Were Selected For Synthesis Of Corresponding Flavones So That The Reactive Hydroxy Moiety Helps In Cyclocondensation With Formation Of Benzopyrone Ring System Which Is Primary Structural Part Of All Flavones. Considerable Increase In Reaction Rate Has Been Observed With Increase In Yield.A Comparative Study Showed That The Microwave Irradiation Condition Afforded Excellent Yield And Shorten Reaction Time. And Microwave Synthesis Of Flavones Are Found To Be Undoubtedly More Economic, Efficient, Ecofriendly And Convenient Than Other Reported Methods As The Equipment Is Cheap, And Reagents Required Are Also Cheap.
\end{abstract}

Key Words: Chalcones, Flavonoids, Microwave Oven.

\section{INTRODUCTION:}

In Latin Flavus means Yellow colour. Flavonoids are yellow color pigments.Defination: Flavonoids are group of aromatic oxygen-bearing heterocyclic pigments widely distributed among higher plants. They constitute most of yellow, red and blue colour in flowers and fruits. ${ }^{15}$ Flavonoids are an extensive group of compounds occurring in plants. They are prominent plant secondary metabolites that have been found in dietary components, including fruits, vegetables, olive oil, tea, and red wine ${ }^{16}$. Besides their physiological role in plants, they have shown to possess antioxidants, anxiolytic, anti-inflammatory, antiviral, antiprotozoal, and anticarcinogenic activities ${ }^{16}$. With reference to the antitumor or related activities, it was described for flavonoids antimitotic activity and/or inhibition of some enzymes like cyclin-dependent kinase, several protein-tyrosine kinases,aromatase, topoisomerase, or protein kinase C. It has been observed that even a high intake of plant based dietary flavonoids is safe and not associated with any adverse health effect. In addition, the interaction of dietary Flavonoids with the gut has numerous implications for human health and Flavonoids in the diet may act as chemo preventive agents against the development of cancer. Apart from their cancer chemo preventive efficacy, such Flavonoids could be developed as an alternative medicine to get the beneficial effects in combination treatment by reducing the dose and associated systemic toxicity of chemotherapeutic agents for similar efficacy. ${ }^{16}$

\section{CHEMISTRY OF FLAVONOIDS:}

The six major subclasses of Flavonoids include the flavones (e.g. apigenin, luteolin), flavononls (e.g. querectin, myricetin), flavanones (e.g. Nanringnin, hespiridin), Catechins or flavanols (e.g. Epicatechin), Anthocyanidis (e.g. Cyanidin, Pelargonidin) and Isoflavones (e.g. Genistein). Falvonoides are largest class of polyphenols with a common structure of diphenylpropanes $\left(\mathrm{C}_{6}-\mathrm{C}_{3}-\mathrm{C}_{6}\right)$ consisting of two aromatic ring linked through three carbons. Biogenetically the A ring usually arises from a molecule of resorcinol or phloroglucinol synthesized from the acetate pathway and has a characteristic hydroxylation pattern at five and seven position. The B ring comes from shikimate pathway and is usually $4,3,4$ or 3, 4, 5 hydroxylated 16 ,<smiles>c1ccc(C2CCc3ccccc3O2)cc1</smiles> 
2.1 GENERAL PROPERTIES: . ${ }^{13}$

- Crystalline compound.

- Soluble in water, dil minerals acids, alkalies and alcohol.

- Precipitated by lead acetate.

- Intensity of yellow color increase with increase in number of hydroxyl group and $\mathrm{pH}$

\subsection{METHODS AVIALABLE FOR SYNTHESIS OF VARIOUS FLAVONOIDS FROM 2'-HYDROXY CHALCONES}

1. Synthesis of Flavanone from 2'-hydroxy chalcones:

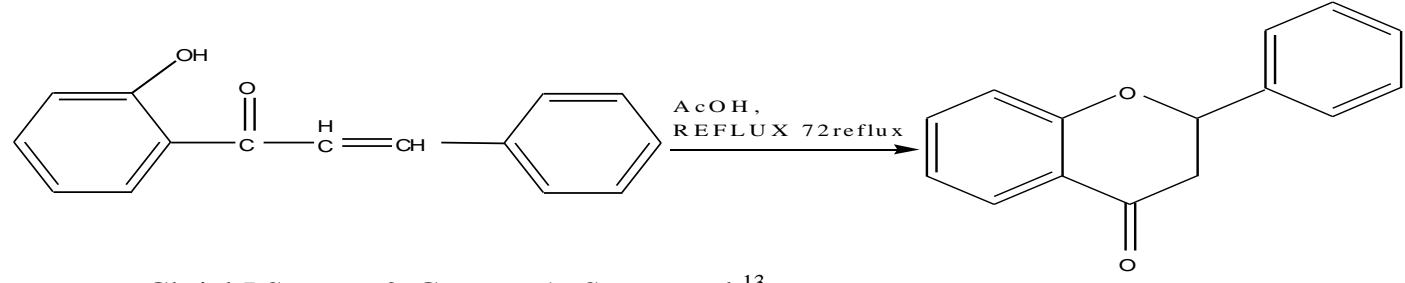

Gbriel J.Sagrera \& Gustavo A. Seone et al ${ }^{13}$

\section{Synthesis of Flavanone from 2'-hydroxy chalcones:}

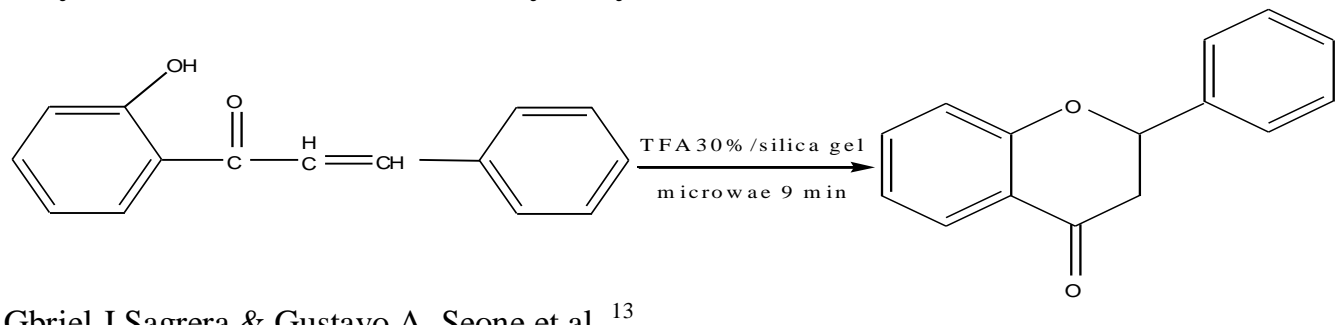

Gbriel J.Sagrera \& Gustavo A. Seone et al ${ }^{13}$

2. Synthesis of Flavones from 2'-hydroxy chalcones:

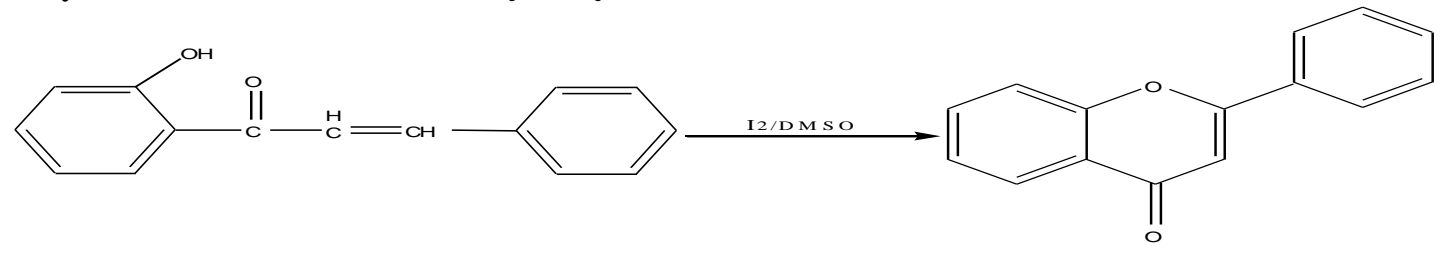

Mauricio Cabrara, Macarena Semoens Gabriela Falchi et al. ${ }^{14}$

3. Synthesis of flavanols from 2'-hydroxy chalcones:

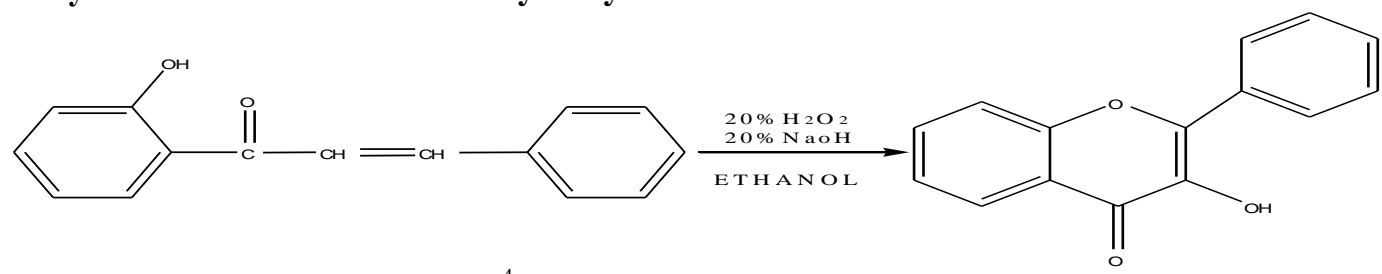

R.B.Palkarand H.E.Master ${ }^{4}$

III. MATERIALS AND METHODS:

[1] .Melting points were taken in open glass capillary using Elico melting point apparatus and were uncorrected

[2] Thin-layer chromatography was done with silica gel $\mathrm{G}$ as adsorbant. The spot were detected by exposure to iodine vapors and U.V.cabinate.

[3] Infra-Red spectra of compounds were recorded on "Schimadzu I.R.408" Spectrophotometer model.

[4] GC-MS spectra were recorded on 'Perkin Elmer Auto System' excel gas chromatography in MVP'S college of pharmacy Nasik.

[5] Proton ${ }^{1} \mathrm{H}$ Nuclear Magnetic Resonance Spectra of compounds were recorded on Broot Spectrophotometer (300MHz) using $\mathrm{CDCl}_{3}$ as solvent, at Pune University Pune. 
[6] All microwave reactions were carried on 'Raga's Electromagnetic System' with automatic power setting from P-1 to P-10.The reactions were start for initial $10 \mathrm{sec}$ and after every $10 \mathrm{sec}$ reaction mixtures were monitored for completion of the reaction with the help of TLC.

\section{SCHEME :}

Scheme: Synthetic route of 3-Hydroxyflavonoids.

TABLE .1: Substitution Table

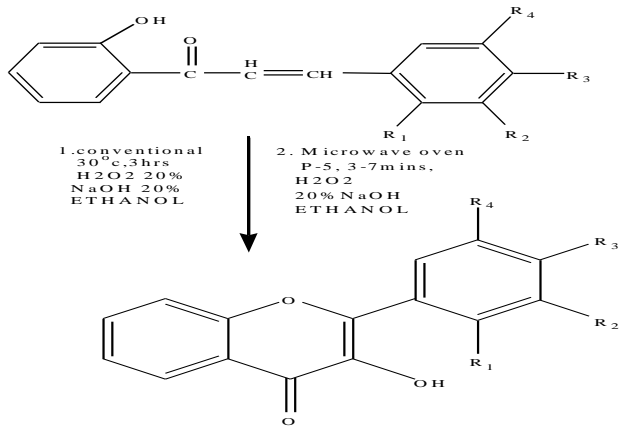

\begin{tabular}{|c|c|c|c|c|}
\hline $\begin{array}{c}\text { Compound } \\
\text { code }\end{array}$ & \multicolumn{4}{|c|}{ Substituents } \\
\hline $\mathrm{F}_{1}$ & $\mathrm{R} 1$ & $\mathrm{R} 2$ & $\mathrm{R} 3$ & $\mathrm{R} 4$ \\
\hline $\mathrm{F}_{2}$ & $-\mathrm{H}$ & $-\mathrm{H}$ & $-\mathrm{H}$ & $-\mathrm{H}$ \\
\hline $\mathrm{F}_{3}$ & $-\mathrm{H}$ & $-\mathrm{H}$ & $\mathrm{OCH} 3$ & $-\mathrm{H}$ \\
\hline $\mathrm{F}_{4}$ & $-\mathrm{H}$ & $-\mathrm{H}$ & $-\mathrm{Cl}$ & $-\mathrm{H}$ \\
\hline $\mathrm{F}_{5}$ & $-\mathrm{H}$ & $\mathrm{OCH} 3$ & $\mathrm{OCH} 3$ & $\mathrm{OCH} 3$ \\
\hline$\Gamma$ & $-r$ & $\mathbf{r}$ & $\mathbf{r}$ & $\mathbf{r}$ \\
\hline
\end{tabular}

TABLE .2: Comparison between conventional and microwave method in synthesis of Flavonoids.

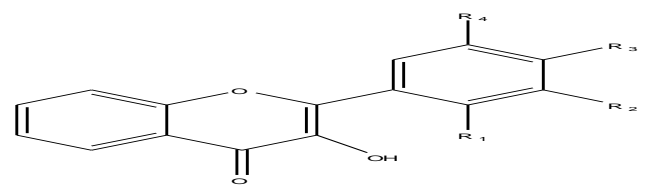

\begin{tabular}{|c|c|c|c|c|c|c|c|c|c|c|}
\hline \multirow[t]{2}{*}{ Compound } & \multirow[t]{2}{*}{ R1 } & \multirow[t]{2}{*}{$\mathrm{R} 2$} & \multirow[t]{2}{*}{ R3 } & \multirow[t]{2}{*}{ R4 } & \multicolumn{2}{|c|}{$\begin{array}{l}\text { Reaction } \\
\text { Time }\end{array}$} & \multicolumn{2}{|c|}{$\begin{array}{c}\text { Yield } \\
{[\%]}\end{array}$} & \multicolumn{2}{|c|}{$\begin{array}{c}\text { Melting point } \\
{\left[{ }^{\circ} \mathrm{c}\right]}\end{array}$} \\
\hline & & & & & $\begin{array}{c}\mathrm{X} \\
{[\mathrm{Hrs}]}\end{array}$ & $\begin{array}{c}\mathrm{Y} \\
{[\mathrm{Min}]}\end{array}$ & $\mathrm{X}$ & $\mathrm{Y}$ & $X^{L}$ & $\mathrm{Y}$ \\
\hline$\overline{F_{1}}$ & $-\mathrm{H}$ & $-\mathrm{H}$ & $-\mathrm{H}$ & $-\mathrm{H}$ & 3 & 3 & 65 & 80 & $\begin{array}{c}167-169 \\
\text { Lit[171- } \\
172]\end{array}$ & $\begin{array}{l}169- \\
171\end{array}$ \\
\hline$\overline{\mathrm{F}_{2}}$ & $-\mathrm{H}$ & $-\mathrm{H}$ & OCH3 & $-\mathrm{H}$ & 3 & 3 & 72 & 85 & $223-227$ & $\begin{array}{l}223- \\
227\end{array}$ \\
\hline $\mathrm{F}_{3}$ & $-\mathrm{H}$ & $-\mathrm{H}$ & $-\mathrm{Cl}$ & $-\mathrm{H}$ & 3 & $61 / 2$ & 65 & 82 & $185-189$ & $\begin{array}{l}184- \\
189\end{array}$ \\
\hline$\overline{\mathrm{F}_{4}}$ & $-\mathrm{H}$ & OCH3 & OCH3 & OCH3 & 3 & 5 & 75 & 78 & $163-165$ & $\begin{array}{l}163- \\
165\end{array}$ \\
\hline $\mathrm{F}_{5}$ & $-\mathrm{Cl}$ & $-\mathrm{H}$ & $-\mathrm{H}$ & $-\mathrm{H}$ & 3 & $41 / 2$ & 78 & 88 & $156-158$ & $\begin{array}{l}155- \\
158\end{array}$ \\
\hline
\end{tabular}

X: Conventional method Y: Microwave method

From table 1and 2 it is concluded that microwave method for synthesis of chalcones and Flavonoids is advantageous over conventional method in terms of time and yield.

\section{PROCEDURE:}

\subsection{Procedure for synthesis of Flavonoids: (Conventional method)}

To a suspension of 1-(2'-hydroxyphenyl)-3-phenyl-2-propen-1-one [0.01mole] in ethanol [85ml] was added $20 \%$ aqueous sodium hydroxide [10ml] with stirring, followed by careful addition of $20 \%$ hydrogen peroxide [18ml]over a period of $0.5 \mathrm{hr}$. The reaction mixture was stirred for $3 \mathrm{hrs}$. at $30^{\circ} \mathrm{c}$ and poured onto crushed ice containing $5 \mathrm{~N}$ HCL . The precipitate was filtered, washed, dried and crystallized from chloroform: methanol [9:1] and pass through column using chloroform as a solvent.

\subsection{Procedure for synthesis of Flavones: (Under microwave)}

Take 0.01 mole of 1-(2'-hydroxyphenyl)-3-phenyl-2-propen-1-one [chalcone], dissolved in ethanol [20ml],to this add [ $10 \mathrm{ml}$ of $20 \%]$ sodium hydroxide and [ $18 \mathrm{ml}$ of $20 \%$ ] hydrogen peroxide and mixture was subjected to microwave irradiation at power- 5 and at $80^{\circ} \mathrm{C}$ the reaction mixture was monitor for completion with TLC after competition of reaction mixture was poured into crushed ice containing $5 \mathrm{~N}$ hydrochloric acid and allow to precipitated then product was filtered, washed with water, dry, and recrystalize by using chloroform: methanol[9:1] and pass through column using chloroform as solvent .Purity of compound was cheeked by TLC. 


\section{SPECTRAL AND ANALYTICAL DATA \\ $\mathrm{F}_{1}$ :-[2'-Hydroxyphenyl]-3-[2-Carboxyphenyl]-2-propen one. \\ $\mathrm{IR}(\mathrm{KBr}): 3500$ (-OHstretching), $1725(\mathrm{C}=\mathrm{O}$ stretching), $1570[\mathrm{C}=\mathrm{C}$ stretching(aromatic)], \\ 1695(COOH stretching ), 2950 [ C-H stretching(aromatic)], 750[C-H Bending (aromatic)], \\ $1630\left[\mathrm{C}=\mathrm{C}\right.$ stretching(aliphatic)],1235(-OH Bending), m.p.133-137 ${ }^{\circ} \mathrm{C}$, yield $80 \%$, \\ mol.wt.268, $\mathrm{C}_{15} \mathrm{H}_{10} \mathrm{O}_{3}$}

\section{$F_{2}: 3$-Hydroxy-4'-Mehoxyflavone.}

$\operatorname{IR}(\mathrm{KBr}): 3280(-\mathrm{OH}$ stretching $), 1715(\mathrm{C}=\mathrm{O}$ stretching $), 1620[\mathrm{C}=\mathrm{C}$ stretching(aromatic) $], 1230(-\mathrm{OH}$ Bending), 1345(C-O-C stretching), 2900[ C-H Stretching(aliphatic)],3010[ C-H Stretching(aromatic)] ${ }^{1}$ NMR $\left[\mathrm{CDCl}_{3}\right] 300 \mathrm{MHz}, 7.70[\mathrm{t}, 1 \mathrm{H}$, Benzene ],7.41[t, 1H, Benzene ], 7.30[d, 1H, Benzene ],7.05 [d, 1H, Benzene ], $3.80\left[\mathrm{bs}\right.$, OH Benzene ],7.57[d, 2H, Benzene ], 8.20[d, 2H, Benzene ],3.89 [s, 3H, OCH3], m/z $268\left(\mathrm{C}_{16} \mathrm{H}_{12} \mathrm{O}_{4}{ }^{+}\right)$, $253\left(\mathrm{C}_{15} \mathrm{H}_{9} \mathrm{O}_{4}{ }^{+}\right), 225\left(\mathrm{C}_{13} \mathrm{H}_{9}{ }^{+}\right), 92\left(\mathrm{C}_{6} \mathrm{H}_{4} \mathrm{O}^{+}\right), 65\left(\mathrm{C}_{5} \mathrm{H}_{5}{ }^{+}\right)$m.p. $223-227^{\circ} \mathrm{C}$, yield 85\%, mol.wt.268, C16H12O41

\section{$F_{3}: 3$-Hydroxy-4'-Chloroflavone}

$\operatorname{IR}(\mathrm{KBr}): 3350(-\mathrm{OH}$ stretching $), 1700(\mathrm{C}=\mathrm{O}$ stretching $), 1625[\mathrm{C}=\mathrm{C}$ stretching(aromatic)], 1310(C-O-C stretching), 800(C-Cl stretching), 3060 [C-H Stretching(aromatic)], 740C-H Bending[aromatic], 1238(-OH Bending),NMR $\left[\mathrm{CDCl}_{3}\right] 300 \mathrm{MHz}: 7.47[\mathrm{t}, 1 \mathrm{H}$, Benzene ], 7.89[t, 1H, Benzene ], 7.43[d, 1H, Benzene ], 7.55[d, $1 \mathrm{H}$, Benzene], $3.64[\mathrm{~s}, 1 \mathrm{H}$, OH Benzene], 7.41[d, 2H, Benzene ], $8.25\{[\mathrm{~d}, 2 \mathrm{H}$, Benzene ], $\mathrm{m} / \mathrm{z}$ $272\left(\mathrm{C}_{15} \mathrm{H}_{9} \mathrm{Cl}^{+}\right), 237\left(\mathrm{C}_{15} \mathrm{H}_{9} \mathrm{O}_{3}{ }^{+}\right), 111\left(\mathrm{C}_{6} \mathrm{H}_{5} \mathrm{Cl}^{+}\right), \quad 209 \quad\left(\mathrm{C}_{11} \mathrm{H}_{17} \mathrm{O}_{2}{ }^{+}\right), \quad 76\left(\mathrm{C}_{6} \mathrm{H}_{4}{ }^{+}\right)$m.p. $185-189^{\circ} \mathrm{C}$,yield $82 \%$,mol.wt. $272, \mathrm{C} 15 \mathrm{H} 9 \mathrm{O} 3 \mathrm{Cl}$.

\section{RESULT AND DISCUSSION:}

In the present investigation some new 2'-hydroxychalcones and their corresponding flavonoid were successfully synthesized using both conventional method and microwave method. These compounds were synthesized with a view to obtain new molecules having possible potent antioxidant activity as such a compounds are extensively reported in the literature to possess antioxidant activity. ${ }^{14}$, In the present scheme 2'hydroxychalcones were used as intermediates for synthesis of flavonoid and similar biosynthetic route is reported to be followed in nature for natural flavonoid. ${ }^{13}$ In this investigation 2 '-hydroxychalcones were selected for synthesis of corresponding flavonoid so that the reactive hydroxy moiety helps in cyclodehydration with formation of benzopyrone ring system which is primary structural part of all flavonoids. ${ }^{3}$ Flavonoids were synthesized from 2'-hydroxychalcones on treatment with sodium hydroxide and hydrogen peroxide in ethanol. By conventional method this reaction requires about 3 hours whereas in microwave method they have been optimally synthesized within 7 mins. with appropriate power setting and time setting.

Thus microwave synthesis of flavinoids and 2'-hydroxychalconesare found to be undoubtedly more

$\checkmark$ Economic

$\checkmark$ Efficient

$\checkmark$ Ecofriendly and

$\checkmark$ Convenient

than other reported methods as the equipment is cheap, and reagents required are cheap and easily available and reaction conditions are very simple and also yield of products are quite good.

\section{CONCLUSION:}

In the present investigation some new flavonoid were successfully synthesized using both conventional method and microwave method. Flavones were synthesized from 2'-hydroxychalcones on treatment with sodium hydroxide and hydrogen peroxide in ethanol. By conventional method this reaction requires about 3 hours whereas in microwave method they have been optimally synthesized within $7 \mathrm{~min}$. with appropriate power setting and time setting. Thus microwave synthesis of flavones and 2'-hydroxychalcones are found to be undoubtedly more Economic, Efficient, Ecofriendly and Convenient than other reported methods as the equipment is cheap, and reagents required are also cheap. sss

\section{REFERENCES:}

[1.] Caddick S. 'Microwave Assisted Organic Reaction' Tetrahedron, 1995, 51, 10403.

[2.] Maria J.Gozalez Moa, Marcos Mandado et al. QTAIM electron density study of natural chalcones. Chemical physics letters, $2007,34,446$

[3.] J. Mojzis, L. Varinska, G. Mojzisova ,I. Kostova , L.Mirossay. Antiangiogenic effects of Flavonoids and Chalcones. Pharmacological research. 2008, 57, 259-265.

[4.] Ruby John Anto, K. Sukumaran, Girija Kuttan ,M.N.A. Rao et al.Anticancer and antioxidant activity of synthetic chalcones and related compounds. Cancer letters. 1995, 97, 33-37

[5.] M.L. Go, X. Wu and X.L. Liu. Chalcones: An update on Cytotoxic and Chemo protective properties, Current medicinal chemistry, 2005, 12,483-499. 
[6.] T. Narender and K. Pupi Reddy. A simple and highly efficient method of chalcones by using Borontrifloride-etherate. Tetrahedron Letters, 2007, 48, 3177-3180

[7.] Swarnlata saraf, Mahendra singh \& Shailesh saraf. A Revive article on Flavonoids: A Neutritional Protection against oxidative \& U V induced cellular damages, pharmacognosy review, 2007, 1, 30-40.

[8.] Han-Wei Chu, Huan-Ting Wuand and Yean-Jang Lee. Rgeoselective hydroxylation of 2-hydroxy chalcones dimethyldioxirane towards polymethoxylated Flavonoids Tetrahedron 2004, 60, 2647-2655.

[9.] Ajay Sharma, Sudhir Bharadwaj, A.S. Maan, Amit Jain and M.D. Kharya. Screening of Antioxidant activity: An overview. Pharmacognosy review, Jul-Dec, 2007, 1, (2)232.

[10.] Ganesh Chandra Jagetia, Krishna J.Malagi, Manjeshwar Shrinath Baliga, et al. Triphala ,an ayurvedik rasayana drug , protects mice against radiation -induced lethality by free radical scavenging, The journal of alternative and complimentary medicine, 2004,10, 971-978.

[11.] Mauricio Cabrara, Macarena Semoens Gabriela Falchi et al.. Synthetic Chalcones, Flavanones and Falvones as antitumoural agents: Biological Evaluation and Structure activity relationships. Bioorganic \& medicinal chemistry, 2007, 15, 3356-3367.

[12.] Ana I.R.N.A. Barros, Artur M.S.Silva et al. Synthesis Experimental and Theoretical NMR study of 2-hydroxychalcones bearing Nitro Subsistent on their B ring, Tetrahedron, 2004, 60, 6513-6521.

[13.] 41. Gbriel J.Sagrera \& Gustavo A. Seone Microwave accelerated Solvent Free Synthesis of Flavonoes.J.braz.chem sec vol, 2005, 16, 4.851-856.

[14.] 27. Mauricio Cabrara, Macarena Semoens Gabriela Falchi et al.. Synthetic Chalcones, Flavanones and Falvones as antitumoural agents: Biological Evaluation and Structure activity relationships. Bioorganic \& medicinal chemistry, 2007, 15, 3356-3367.

[15.] 18. Dr. Mohammed Ali, Dictionary of Pharmacy, Second Edition, Tara publishers Dhli, Pp.56.

[16.] Swarnlata saraf, Mahendra singh \& Shailesh saraf. A Revive article on Flavonoids: A Neutritional Protection against oxidative \& U V induced cellular damages, pharmacognosy review, 2007, Vol I, 30-40. 